\title{
A New Approach for Optimal Sizing of Standalone Photovoltaic Systems
}

\author{
Tamer Khatib, ${ }^{1}$ Azah Mohamed, ${ }^{1}$ K. Sopian, ${ }^{2}$ and M. Mahmoud ${ }^{3}$ \\ ${ }^{1}$ Department of Electrical, Electronic \& System Engineering, Faculty of Engineering \& Built Environment, \\ National University of Malaysia, Selangor, 43600 Bangi, Malaysia \\ ${ }^{2}$ Solar Energy Research Institute, National University of Malaysia, Selangor, 43600 Bangi, Malaysia \\ ${ }^{3}$ Department of Electrical Engineering, Engineering Faculty, An-Najah National University, Nablus 97300, Palestine
}

Correspondence should be addressed to Tamer Khatib, tamer_khat@hotmail.com

Received 16 August 2011; Accepted 16 November 2011

Academic Editor: Peter Rupnowski

Copyright (๑) 2012 Tamer Khatib et al. This is an open access article distributed under the Creative Commons Attribution License, which permits unrestricted use, distribution, and reproduction in any medium, provided the original work is properly cited.

This paper presents a new method for determining the optimal sizing of standalone photovoltaic (PV) system in terms of optimal sizing of PV array and battery storage. A standalone PV system energy flow is first analysed, and the MATLAB fitting tool is used to fit the resultant sizing curves in order to derive general formulas for optimal sizing of PV array and battery. In deriving the formulas for optimal sizing of PV array and battery, the data considered are based on five sites in Malaysia, which are Kuala Lumpur, Johor Bharu, Ipoh, Kuching, and Alor Setar. Based on the results of the designed example for a PV system installed in Kuala Lumpur, the proposed method gives satisfactory optimal sizing results.

\section{Introduction}

Based on the fact that PV systems are clean, environment friendly, and secure energy sources, PV system installation has played an important role worldwide. However, the drawback of PV system is the high capital cost compared with conventional energy sources. Currently, many research works are carried out focusing on optimization of PV systems so that the number of PV modules, capacity of storage battery, capacity of inverter, and PV array tilt angle can be optimally selected. PV system size and performance strongly depend on metrological variables such as solar energy and ambient temperature, and therefore, to optimize a PV system, extensive studies related to the metrological variables have to be done [1].

The research works related to PV system size optimization can be found in [2-14]. In [2], the probabilistic approach is used to optimize PV systems by considering a probability function which is expressed as the probability of losing load in terms of storage battery, PV array energy output, and load demand. Therefore, the determination of optimum storage battery is done based on the reliability of the PV system, and the optimum PV system array size is calculated using the worst month method. In [3], an optimum design for PV systems in Sudan is developed based on a clear sky model for global solar prediction in Sudan. The optimization of PV panel tilt angle was done based on Jordan and Liu model for solar energy incident on a tilt surface. However, to optimize the array and storage sizes, it is assumed that the stored energy in a storage battery is equal to the difference between the load power and PV array generated power. In Europe, optimization of PV system is done for three sites in which optimization considers sizing curves derivation and minimum storage requirement [4]. To avoid any load interruption, the PV array size is designed based on the worst monthly average of solar energy. As for finding the minimum storage requirement, the same method used in plotting sizing curves is used, and the minimum storage requirement is calculated for each year of the used historical data. In [5], a PV system model is developed to optimize its size based on a well-defined solar energy potential and load. The developed model contains models for PV array, storage battery, and charge regulator. However, the optimization considers the combined minimum cost with minimum loss of load probability. In [6], optimization of PV systems in Algeria is implemented by dividing the regions into four zones using the sky clearness index. The optimization of PV systems is based on loss of load probability calculated 
using the daily solar energy. After calculating the loss of load probability values, sizing curves for 12 sites in Algeria have been generated using a simulation program.

Optimization of PV systems in Greece has been done based on zero load rejection condition which investigates that the desired PV system is always able to supply load without any cutoffs [7]. The simulation program called as the "PHOTOV-III" is used to set the number of PV modules and capacity of battery based on load demand. In the simulation, the number of PV modules is fixed while the battery capacity value is kept changing based on load demand until zero load rejection. After that, the number of PV module is increased, and the simulation is repeated. The simulation generates sizing curves based on zero load rejection condition. In [8], optimization of PV systems in Delhi is done using the loss of power probability. A defined load and daily solar energy has been used to calculate the loss of power probability. Then sizing curve is generated based on the calculated loss of power probability. The number of PV modules and battery capacity are also evaluated based on the minimum cost. An analytical method for sizing of PV systems based on the concept of loss of load probability is also developed [9]. The method considers the standard deviation of loss of load probability and another two new parameters: annual number of system failures and standard deviation of annual number of failures. The optimization of PV array tilt angle is also done so as to maximize the collected yield. In [10], optimization of standalone PV systems in Iran is presented using the available daily global solar radiation determined from cloud cover. Here, the optimization of PV system considers the optimum tilt angle for the solar panels in Iran. After finding the optimum tilt angle, the size of PV system for a specific load demand is calculated using the worst month method. Optimization of PV systems in Spain and North America has been presented in $[11,12]$ by using a regression model for calculating PV array capacity. This model is represented by a linear equation in terms of mean yearly of global solar energy, minimum value of monthly global solar energy, minimum value of monthly clearness index, and the variability of monthly daily solar energy. The variability of monthly daily solar energy is defined as the difference between mean yearly of global solar energy and minimum value of monthly global solar energy divided by the mean yearly of global solar energy. To validate the accuracy of the developed model, the output results of the model are compared with the method for generating sizing curves $[11,12]$. In [13], an optimization method for PV system based on observed time series of solar radiation has been presented. Here, the sizing curve is constructed based on the three climate zones in UK, and a curve-fitting method considering an exponential function is applied so as to define the optimum sizes of PV array and battery storage.

Optimal sizing of a standalone PV system in Kuala Lumpur, Malaysia has been presented in [14]. The optimization method considers three steps in which the first step involves estimation of PV array output based on one-year solar energy records. It is assumed that the output energy of a PV array is a function of peak sun shine hours, ambient temperature, and wire and dust losses. The second step is

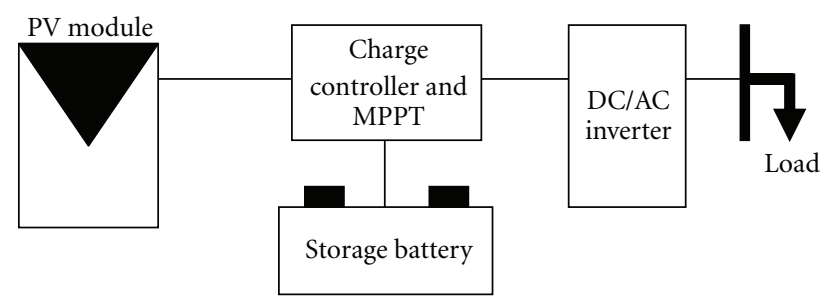

Figure 1: Typical PV system components.

estimating the daily status of the battery storage which is done based on the previous amount of the stored energy, PV array output energy, load energy demand, battery's efficiency, and inverter's efficiency. In the third step, the loss of load probability is defined, and then the system cost is formulated in terms of the cost of PV array, batteries, and other components. However, the system cost equation is partially derived and has to be solved graphically. Thence, the plotted graph contains two lines; one represents the loss of load probability while the other line results from the partial derivate of the system cost equation. The tangent of these two lines gives the optimum size of PV. However, this method [14] has several disadvantages, such that, the sizing curve has to be constructed for each particular load, uses graphical solution rather than a precise formula to calculate the optimum PV size, and determines optimal PV sizing for Kuala Lumpur region only and do not consider other regions in Malaysia. To overcome these limitations, the proposed research attempts to derive optimization formulas for a standalone PV system that can be applied for the whole of Malaysia. These formulas are useful for calculating the optimum PV array and battery storage capacity based on the desired loss of load probability without having to use graphical solution. This work uses the long term solar energy data (1975-2004) provided by the Solar Energy Research Institute (SERI), Universiti Kebangsaan Malaysia (UKM).

\section{Energy Flow Analysis for a Standalone PV System}

Figure 1 shows a typical PV system consisting of a PV module/array, power conditioner such as charge controller or maximum power point tracking controller, storage batteries, inverter, and load.

In general, PV array collects energy from the sun and converts it to DC current. The DC current flows through a power conditioner to supply load through an inverter. The daily output or energy produced by a PV module/array is given by

$$
E_{\mathrm{PV}}=A_{\mathrm{PV}} * E_{\mathrm{sun}} * \boldsymbol{\eta}_{\mathrm{PV}} * \boldsymbol{\eta}_{\mathrm{inv}} * \boldsymbol{\eta}_{\mathrm{wire}},
$$

where Apv is the area of the PV module/array and $E_{\text {sun }}$ is daily solar irradiation. $\eta_{\mathrm{PV}}, \eta_{\mathrm{inv}}$, and $\eta_{\text {wire }}$ are efficiencies of PV module, inverter, and wires, respectively. 
The energy at the front end of a PV system or at the load side is given by

$$
\text { Energy difference }=\sum_{i=1}^{366}\left(E_{\mathrm{PV}}-E_{L}\right),
$$

where $E_{L}$ is the load energy demand.

The result of (2) is that it may be either positive $\left(E_{\mathrm{PV}}>\right.$ $\left.E_{L}\right)$ or negative $\left(E_{\mathrm{PV}}<E_{L}\right)$. If energy difference is positive then there is an excess in energy (EE), while if it is negative then there will be an energy deficit (ED). The excess energy is stored in batteries in order to be used in case of energy deficit. Meanwhile, energy deficit can be defined as the disability of the PV array to provide power to the load at a specific time. The annual energy amount supposed to be stored in the storage battery is given by

$$
E_{B}=\left(\sum \text { Energy excess }-\sum \text { Energy deficit }\right) \boldsymbol{\eta}_{\text {charge }},
$$

where $\boldsymbol{\eta}_{\text {charge }}$ is the charging efficiency of a storage battery.

Using (3), the expected daily storage battery capacity, $C_{B}$, can be calculated as follows:

$$
C_{B}=\frac{E_{B}}{366} .
$$

\section{Proposed Optimization Method}

In designing PV systems, it is important to know the power supply availability. $100 \%$ availability of a power supply means that the power supply is able to cover load demand in a year without any interruptions. On the other hand, $0.0 \%$ availability of a power supply means that the power supply is not able to cover load demand in a year at all. This means that high PV systems availability leads to high-reliability and vice versa. However, high-reliability PV systems incur high initial cost, and, therefore, it is not feasible to design PV systems with very high availability rates. The availability of a PV system is expressed in a statistical value which is the loss of load probability (LLP). LLP is the ratio of annual energy deficits to annual load demand, and it is given by

$$
\text { LLP }=\frac{\sum_{i=1}^{366} \text { Energy deficits }_{i}}{\sum_{j=1}^{366} \text { Energy demand }_{j}} .
$$

To generalize the proposed optimization, the following parameters are defined for PV array and battery storage sizing as follows:

$$
\begin{gathered}
C_{A}=\frac{C_{\mathrm{PV}}}{L}, \\
C_{s}=\frac{C_{B}}{L},
\end{gathered}
$$

where $C_{B}, C_{\mathrm{PV}}$, and $L$ are battery capacity at specific load, $\mathrm{PV}$ array capacity at specific load, and load, respectively.

Considering that the relation between $C_{A}$ and LLP is exponential while the relation between $C_{A}$ and $C_{S}$ is linear
[2-14], the following formulas are derived for optimum values of $C_{A}$ and $C_{S}$

$$
\begin{gathered}
\text { optimum } C_{A}=c_{1} e^{C_{2} L L P}+c_{3} e^{C_{4} L L P}, \\
\text { optimum } C_{s}=c_{5}+c_{6} C_{A} .
\end{gathered}
$$

Figure 2 shows the proposed optimization algorithm in which the optimization process starts with defining some constants and initials such as load demand, PV efficiency, inverter efficiency, wire efficiency, and charging efficiency. Then a series of daily solar irradiation for the targeted site is obtained. This series must be calculated based on long historical data in order to achieve an accurate PV system size. However, after defining the load demand (Wh/day), a range of PV array area must be set. Each value of PV array area will generate different values of output energy using (1). From each PV array area value, $C_{A}$ is then calculated. Subsequently, the energy difference is calculated using (2). During the calculation of energy difference, arrays of EE and ED values will be constructed. At specific PV array area, LLP, $C_{s}$, and $C_{A}$ are calculated and stored in arrays. This loop will be repeated till the max range of PV array area is reached. Finally, plots of LLP versus $C_{A}$ and $C_{s}$ versus $C_{A}$ are constructed, and from these plots, curve-fitting equations are derived using the MATLAB fitting toolbox so as to derive $C_{A}$ as a function of LLP and $C_{s}$ as a function of $C_{A}$ as described in (7).

\section{Results and Analysis}

The proposed method for optimizing PV systems has been applied for five sites in Malaysia, namely, Kuala Lumpur, Johor Bharu, Ipoh, Kuching, and Alor Setar. The long solar energy term data between the year 1975 to 2005 for these sites have been used for this purpose. Figure 3 shows the plots of $C_{A}$ versus LLP for the five sites while Figure 4 shows the relation between $C_{s}$ versus $C_{A}$.

The MATLAB fitting toolbox is used to fit the curves which are plotted in Figures 3 and 4. Table 1 shows the coefficients of (7) for the chosen sites.

4.1. Case Study Based on Malaysian Weather Profile. The optimal sizing of PV system which considers the capacities of PV array and battery storage using the proposed method is compared to the method in [14] as both methods are applicable for PV systems installed in Malaysia. Using the data for daily load demand $(2.215 \mathrm{kWh} /$ day $)$, loss of load probability (0.01), and location coordinate (Kuala Lumpur), the method in [14] obtained the optimum PV array and battery storage sizes of $720 \mathrm{Wp}$ and $135 \mathrm{Ah}$, respectively, with a LLP of 0.01 . Similar data of daily load demand $(2.215 \mathrm{kWh} /$ day), loss of load probability (0.01), and location coordinate (Kuala Lumpur) are also used to determine the optimal sizing of PV system using the proposed method. Using the coefficient values for Kuala Lumpur as shown in Table 1, the calculated optimum $C_{A}$ and $C_{S}$ are 2.02 and 0.793 , respectively. This means that the optimum ratings for the PV array and battery storage of the proposed method are $725 \mathrm{Wp}$ and $146 \mathrm{Ah}$, respectively. It is noted that the 


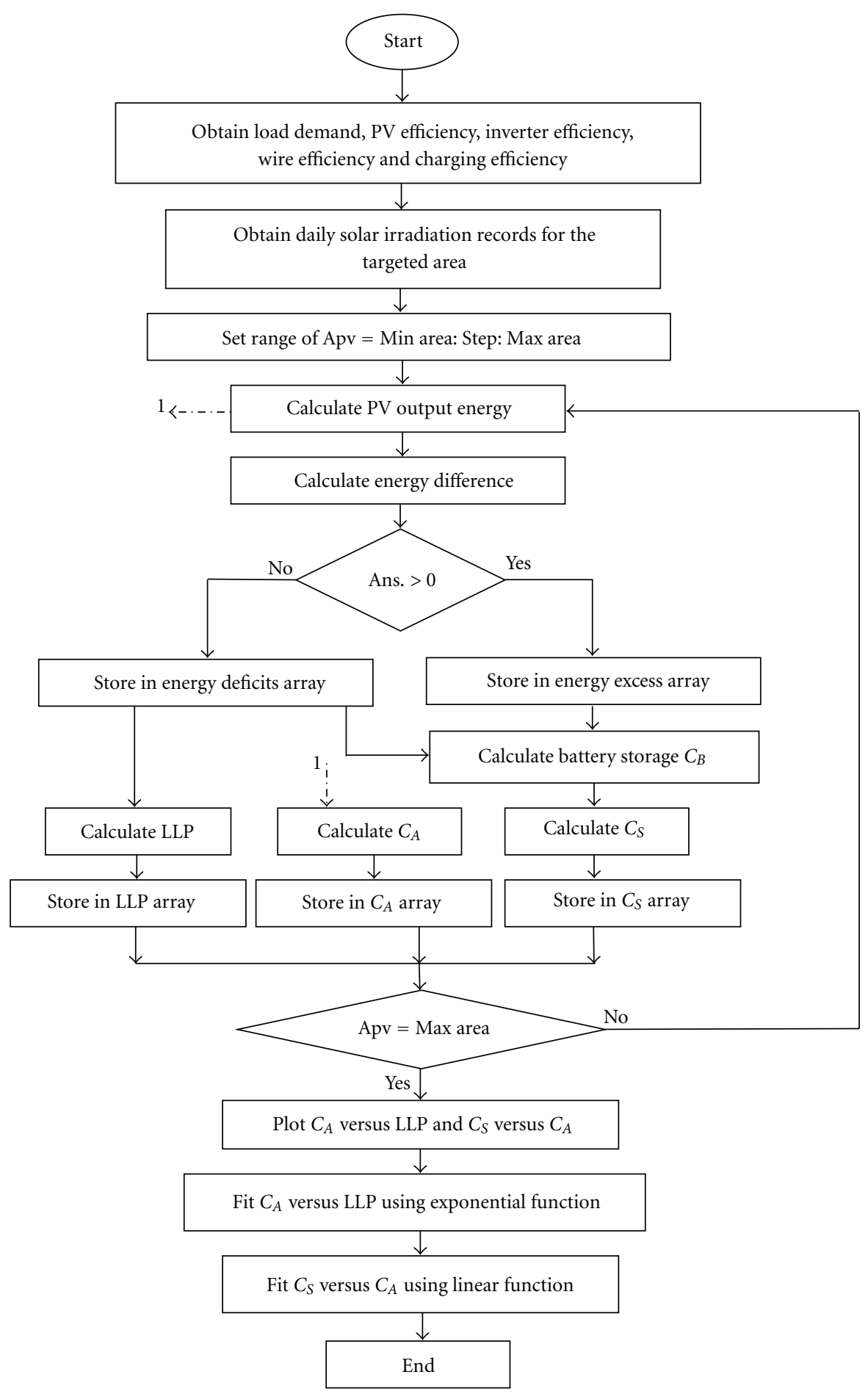

FIgURE 2: Proposed optimization algorithm.

optimum ratings for the PV array and battery storage of the proposed method and the method in [14] are comparable except that the optimum battery storage capacity is slightly higher than that in [14]. The difference in this value is due to different solar energy data used in which in [14] only one year (1999) solar energy data is used while in the proposed method, long term solar energy data (1975-2005) have been used.
The proposed method is considered to be better than the method in [14] due to several reasons; firstly, the method in [14] deals with data for Kuala Lumpur only while the proposed method deals with five main sites in Malaysia. Secondly, the proposed method provides two simple formulas to find the optimum size of a PV system while the method in [14] is based on plotting sizing curves and then search for the minimum cost using the first derivative of system's cost 


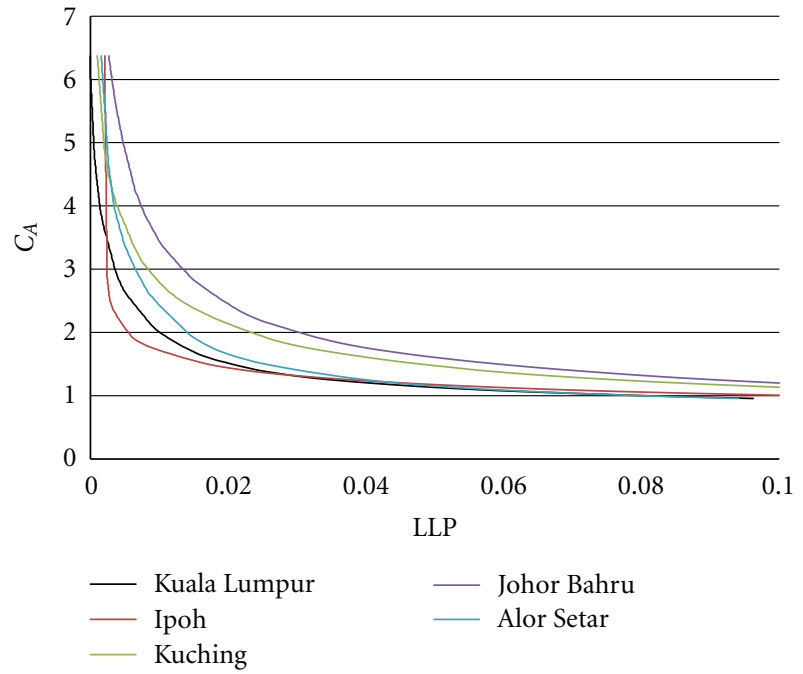

Figure 3: Optimum PV array sizes at different LLPs.

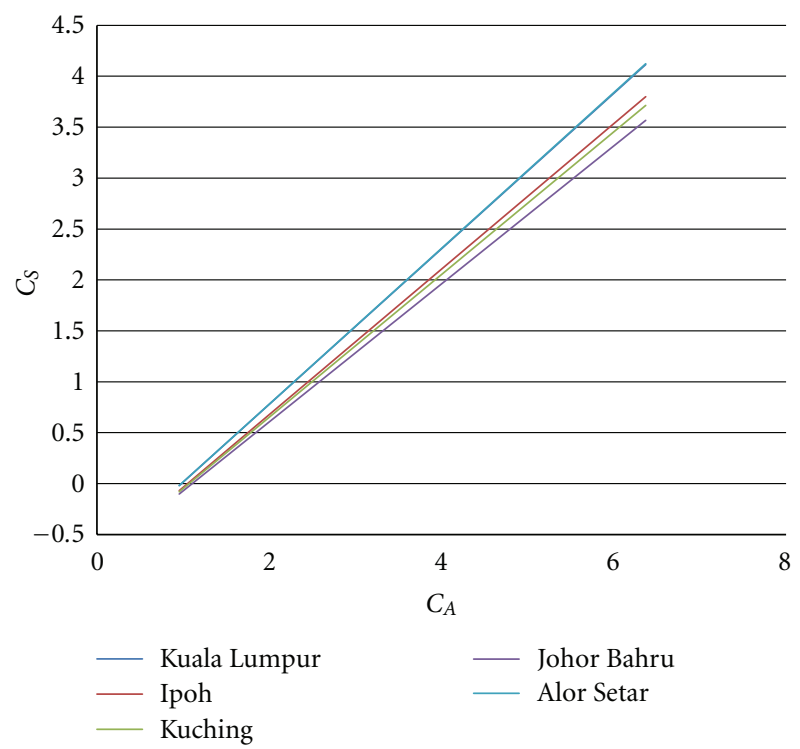

Figure 4: Optimum battery storage sizes $\left(C_{s}\right)$ at different PV array sizes $\left(C_{A}\right)$.

Table 1: Coefficients C1-C6 of (7) after curve fitting.

\begin{tabular}{lcccccc}
\hline & $\mathrm{C} 1$ & $\mathrm{C} 2$ & $\mathrm{C} 3$ & $\mathrm{C} 4$ & $\mathrm{C} 5$ & $\mathrm{C} 6$ \\
\hline Kuala Lumpur & 2.355 & -140 & 1.529 & -5.938 & 0.7637 & -0.75 \\
Johor Bharu & 4.117 & -120 & 2.433 & -8.310 & 0.6776 & -0.75 \\
Ipoh & 1.151 & -142 & 1.509 & -4.858 & 0.7140 & -0.75 \\
Kuching & 3.182 & -167 & 2.426 & -9.817 & 0.7000 & -0.75 \\
Alor Setar & 3.613 & -142 & 1.667 & -7.051 & 0.7648 & -0.75 \\
\hline Average & 2.884 & -142 & 1.913 & -7.195 & 0.7240 & -0.75 \\
\hline
\end{tabular}

equation. Thirdly, the proposed method is valid for all loads, while the method in [14] deals with each load as an individual case. In [14], to determine the optimum PV system size for a specific load, a sizing curve based on the provided

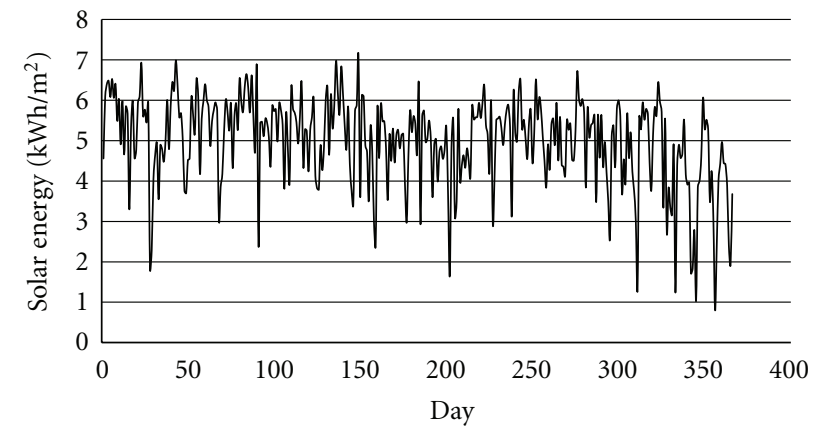

Figure 5: Daily solar energy for Kuala Lumpur.

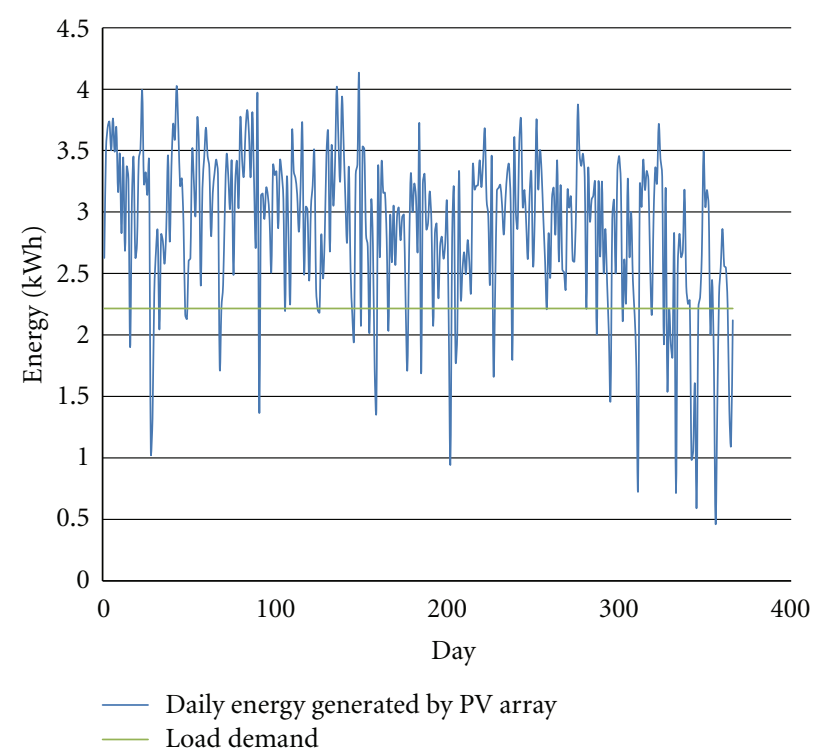

Figure 6: Generated energy by the designed PV array.

load should be plotted. That's to say, the method in [14] needs to perform simulation for each specific load, while the optimum size of PV system by the proposed method can be easily determined by using the two simple equations of (7).

4.2. Designed PV System Analysis. The designed PV system is based on the optimum ratings for the PV array and battery storage of the proposed method which are $725 \mathrm{Wp}$ and $146 \mathrm{Ah}$, respectively, and the average daily solar energy data for Kuala Lumpur as shown in Figure 5. The annual average solar energy is $4.9 \mathrm{kWh} / \mathrm{m}^{2}$ with December having the worst solar energy average, while May has the best solar energy average in one year. The energy produced by the designed PV array is then calculated with respect to the load, and the energy is plotted as shown in Figure 6. The average energy generated by the designed PV array is $2.9 \mathrm{kWh}$. This energy is supposed to cover the load demand while the excess energy is stored in the battery. In the case of fully charged batteries, the excess energy will be dumped using a dumping load. Figure 7 shows the energy balance of the system in which negative energy indicates that the battery is used to supply the load, 


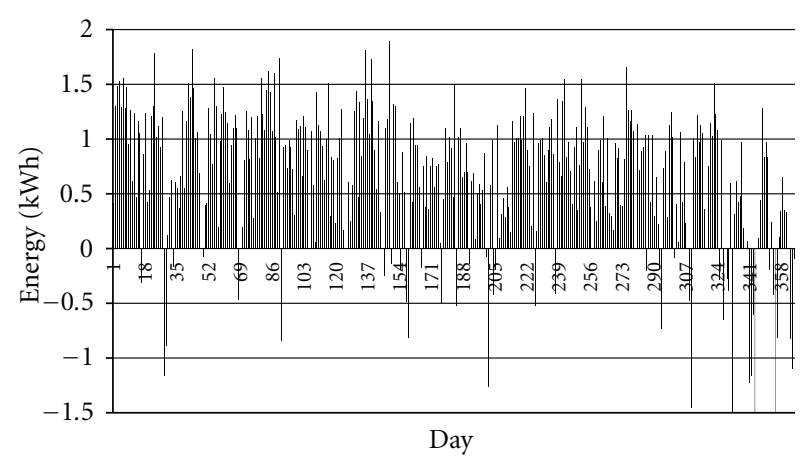

FIgURE 7: Energy balance for designed PV system.

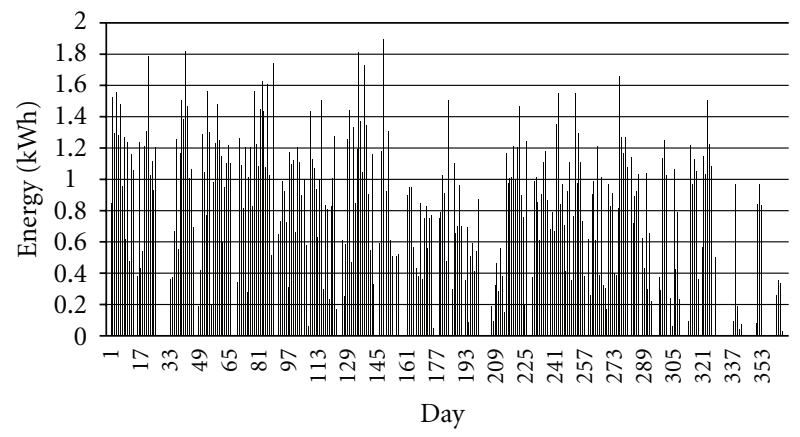

Figure 8: Dumped energy for the designed PV system.

while the positive net energy indicates that this energy has to be stored in the battery or dumped.

Figure 8 shows the net energy which needs to be dumped. The daily average of dumped energy is $0.67 \mathrm{kWh}$ while the sum of the dumped energy per year is $244 \mathrm{kWh}$. Dumping this daily energy of $0.67 \mathrm{kWh}$ may be considered feasible than storing it in a battery considering that the stored energy in a battery with $80 \%$ charging efficiency is $0.54 \mathrm{kWh} /$ day. The cost of dumped energy per year based on kWh unit price is $65 \$$ per year. Installing battery storage to save this amount of energy may cost more than dumping since the price of $\mathrm{Ah} / 12 \mathrm{~V}$ of battery storage is about $2.5-3.5 \$$, and furthermore battery storage needs changing every 4 to 5 years. Therefore, the most appropriate solution to the problem of net energy is to add a load which does not require a stable energy demand. A suitable load for this purpose is a water pump which is used for pumping domestic water in which the amount of pumped water depends on the excess energy.

Figure 9 shows the state of charge (SOC) of the battery storage for a year (1-366 days). The SOC value of 1.0 indicates that the battery is not used while SOC value is less than 1.0 means that the battery is used. From the figure, the battery supplies power to the load for 79 days which is about $22 \%$ of the days in a year. From the 79 days, the battery reaches its allowable minimum SOC (0.2) twelve times, while SOC value greater than 0.6 is about $62 \%$ of the 79 days. When the SOC reaches a value of 0.2 , some load will be lost, and this is the loss of load days as shown in Figure 10. The figure shows the percentage of covered load demand during loss of load days. During a year, the load is lost for 10 days which

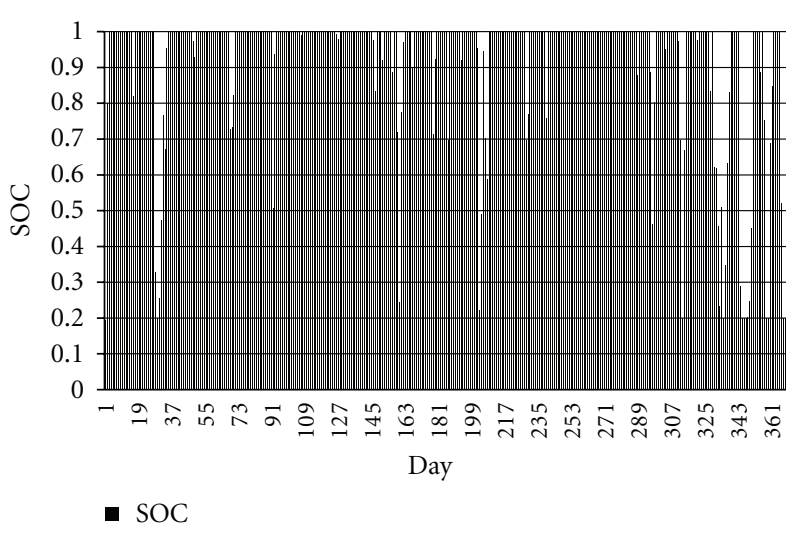

Figure 9: Battery storage SOC for the designed PV system.

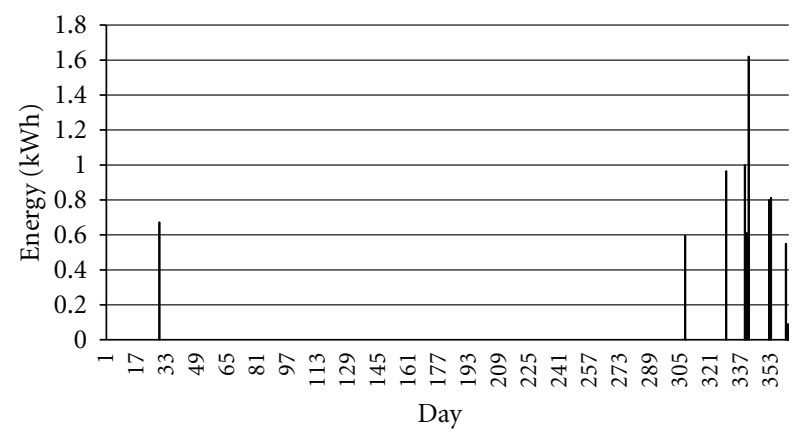

Figure 10: Loss of load days for the designed PV system.

means $2.7 \%$ of a year. However, most of load loss incidences happen in December and November. Form the figure, in most load loss days, $60 \%$ of load demand is covered, and the loss of load probability is $0.95 \%$.

\section{Conclusion}

A new method for optimal sizing of a standalone PV system has been presented. The capacity of PV array is optimally selected based on the desired loss of load probability, while the battery storage size is selected based on the optimum PV array capacity. The proposed method has been used to optimize PV systems at five sites in Malaysia. However, to ensure the validity of the proposed method, a designed example of a previous work is selected as a benchmark. The proposed method gives very close values to the taken benchmark method, but the proposed method is better than the benchmark method because of its simplicity and wide validity.

\section{References}

[1] T. Khatib, "A review of designing, installing and evaluating standalone photovoltaic power systems," Journal of Applied Sciences, vol. 10, no. 13, pp. 1212-1228, 2010.

[2] P. Arun, R. Banerjee, and S. Bandyopadhyay, "Optimum sizing of photovoltaic battery systems incorporating uncertainty through design space approach," Solar Energy, vol. 83, no. 7, pp. 1013-1025, 2009. 
[3] O. E. Elsheikh Ibrahim, "Sizing stand-alone photovoltaic systems for various locations in Sudan," Applied Energy, vol. 52, no. 2-3, pp. 133-140, 1995.

[4] A. Fragaki and T. Markvart, "Stand-alone PV system design: results using a new sizing approach," Renewable Energy, vol. 33 , no. 1, pp. 162-167, 2008.

[5] G. B. Shrestha and L. Goel, "A study on optimal sizing of stand-alone photovoltaic stations," IEEE Transactions on Energy Conversion, vol. 13, no. 4, pp. 373-378, 1998.

[6] A. Hadj Arab, B. Ait Driss, R. Amimeur, and E. Lorenzo, "Photovoltaic systems sizing for Algeria," Solar Energy, vol. 54, no. 2, pp. 99-104, 1995.

[7] J. K. Kaldellis, "Optimum technoeconomic energy autonomous photovoltaic solution for remote consumers throughout Greece," Energy Conversion and Management, vol. 45, no. 17, pp. 2745-2760, 2004.

[8] N. D. Kaushika, N. K. Gautam, and K. Kaushik, "Simulation model for sizing of stand-alone solar PV system with interconnected array," Solar Energy Materials and Solar Cells, vol. 85, no. 4, pp. 499-519, 2005.

[9] R. Posadillo and R. López Luque, "Approaches for developing a sizing method for stand-alone PV systems with variable demand," Renewable Energy, vol. 33, no. 5, pp. 1037-1048, 2008.

[10] J. Samimi, E. A. Soleimani, and M. S. Zabihi, "Optimal sizing of photovoltaic systems in varied climates," Solar Energy, vol. 60, no. 2, pp. 97-107, 1997.

[11] M. Sidrach-de-Cardona and L. M. López, "A simple model for sizing stand alone photovoltaic systems," Solar Energy Materials and Solar Cells, vol. 55, no. 3, pp. 199-214, 1998.

[12] M. Sidrach-de-Cardona and L. Mora López, "A general multivariate qualitative model for sizing stand-alone photovoltaic systems," Solar Energy Materials and Solar Cells, vol. 59, no. 3, pp. 185-197, 1999.

[13] T. Markvart, A. Fragaki, and J. N. Ross, "PV system sizing using observed time series of solar radiation," Solar Energy, vol. 80, no. 1, pp. 46-50, 2006.

[14] W. X. Shen, "Optimally sizing of solar array and battery in a standalone photovoltaic system in Malaysia," Renewable Energy, vol. 34, no. 1, pp. 348-352, 2009. 


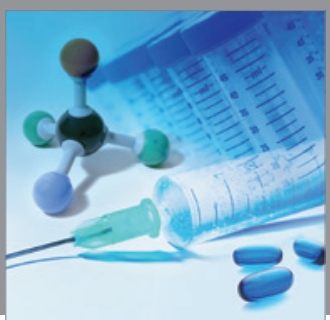

International Journal of

Medicinal Chemistry

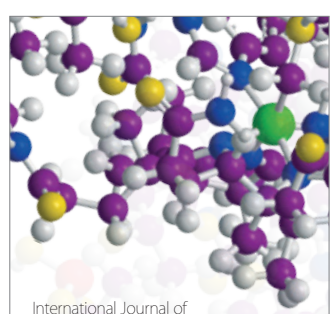

Carbohydrate Chemistry

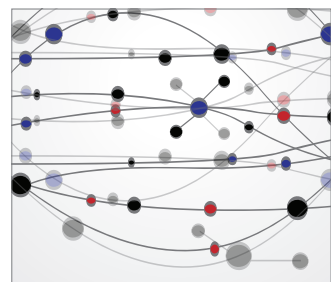

The Scientific World Journal
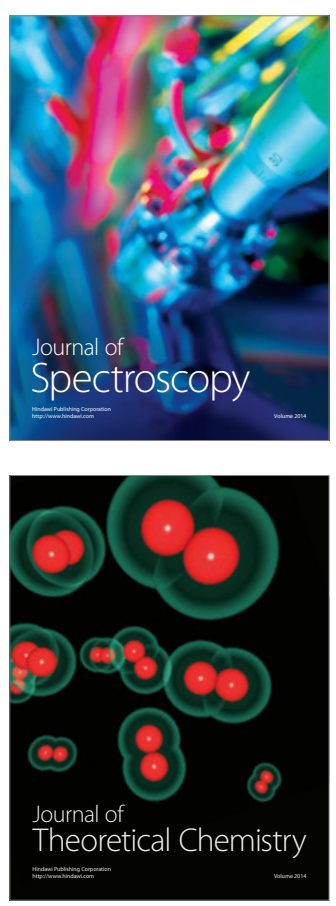
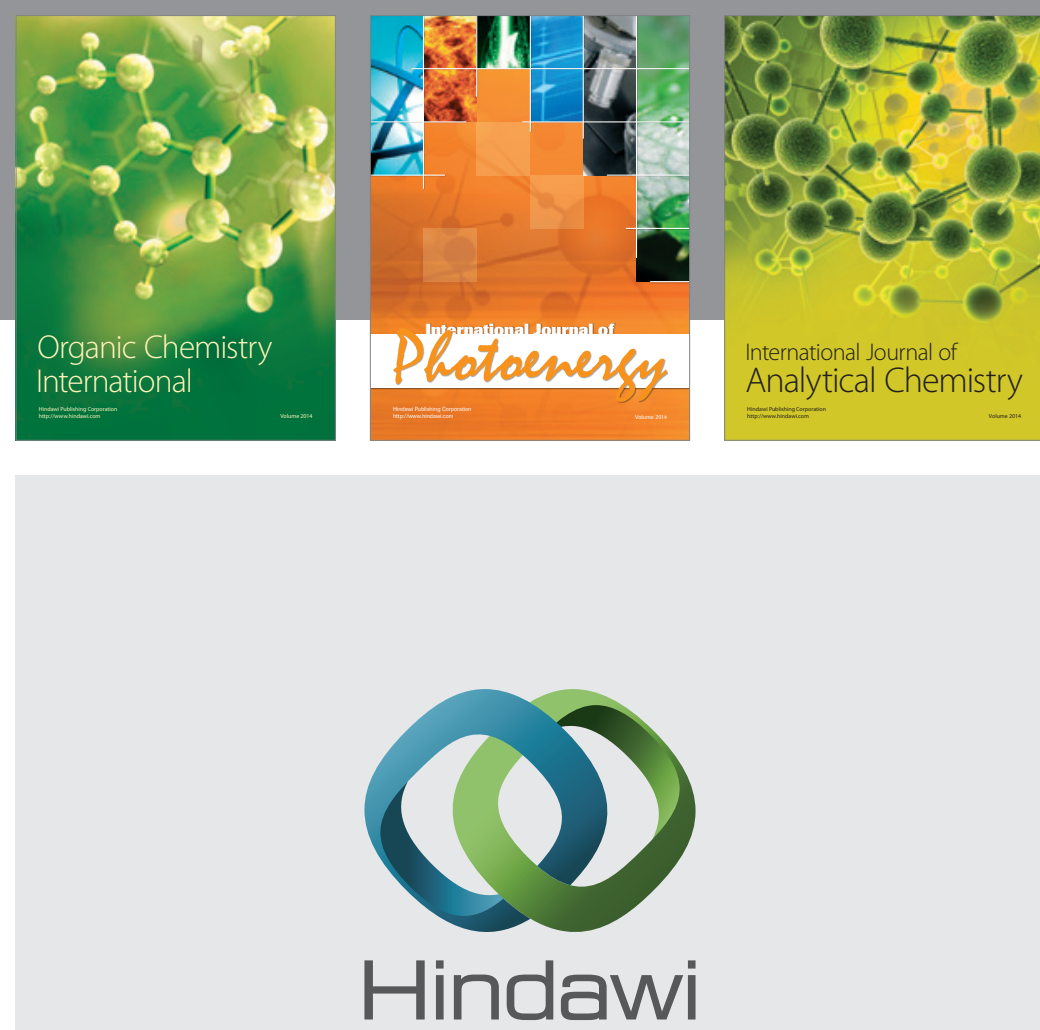

Submit your manuscripts at

http://www.hindawi.com
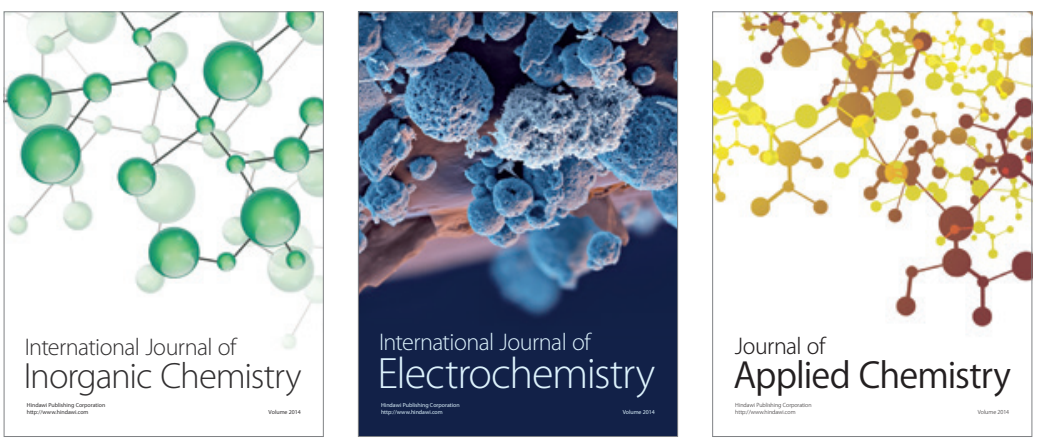

Journal of

Applied Chemistry
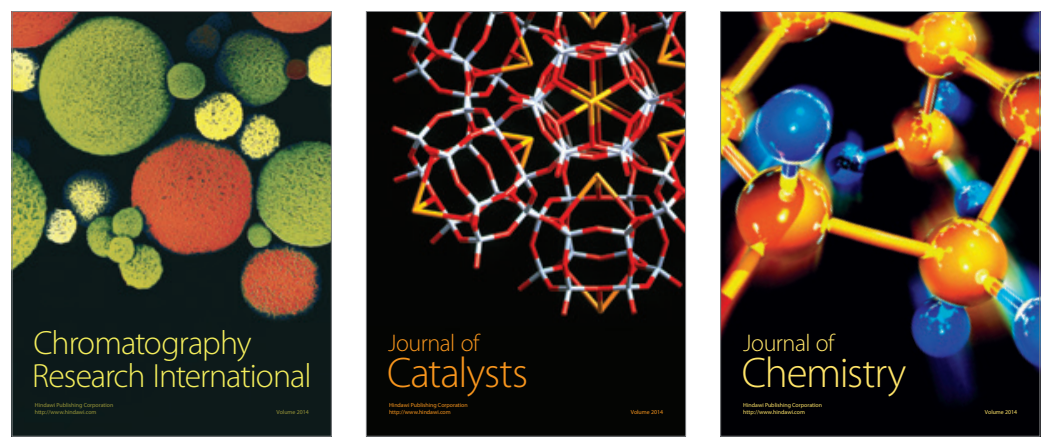
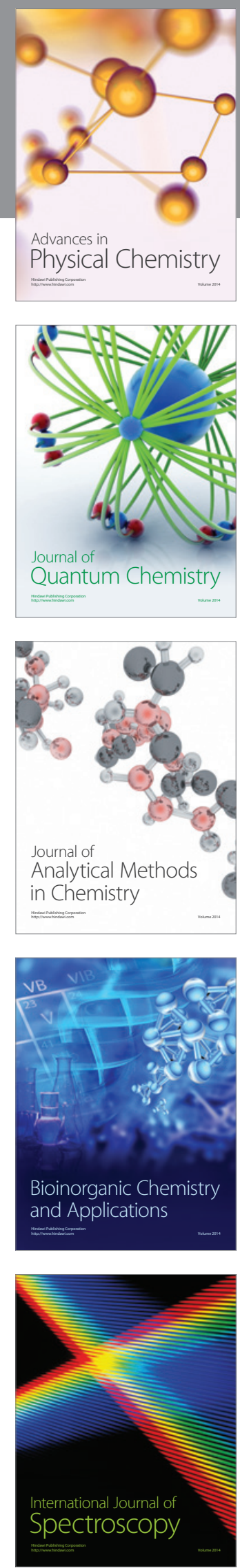